\title{
EVALUATION OF WATER SORPTION, SOLUBILITY AND PH OF FLUORIDE AND STRONTIUM FLUORIDE MODIFIED CALCIUM SILICATE BASED CEMENT
}

\author{
Hosam Muhammad Elsayed *, Muhammad Shokry Ali ${ }^{* *}$, Muhammad Abbas Masoud ${ }^{* * *}$
}

\begin{abstract}
Objective: The objective of this study was intended to evaluate water sorption, solubility and $\mathrm{pH}$ of fluoride and strontium fluoride modified calcium silicate based cement._Materials and Methods: Material used in this study were divided into three main groups. Group I: Calcium silicate based material (biodentine) is a control group, Group II: Strontium fluoride modified calcium silicate based material and Group III: Fluoride modified calcium silicate based material. Each main group was subdivided into two subgroups according to test type ( $\mathrm{pH}$ and water sorption and solubility tes. Results: According to water sorption and solubility test, biodentine recorded lowest water sorption and solubility, followed by strontium fluoride modified biodentine, followed by fluoride modified biodentine. According to $\mathrm{pH}$, biodentine have high $\mathrm{pH}$ followed by fluoride modified biodentine then by strontium fluoride modified biodentine. Also $\mathrm{pH}$ values declined by time from 24 hours, one week and four weeks. Conclusion: Modification of biodentine with strontium fluoride and fluoride has no considerable effect on the tested properties of biodentine.
\end{abstract}

Key Words: Biodentine, physical properties, strontium fluoride, water sorption.

\section{INTRODUCTION}

Biomaterials science aims to develop materials that are ideal mechanically, physically and biologically. Mineral trioxide aggregates (MTA) is tricalcium silicate cement that was initially indicated for surgical endodontics but over time found multiple other applications such as vital pulp therapy, perforation repair, apexification and apexogenesis. The main drawbacks of MTA include its potential to cause tooth discoloration, difficult handling properties due to grainy consistency, cost ineffectiveness and long setting time between 40 minutes and 72 hours ${ }^{(1)}$.

The limitations of MTA led to developing biodentine using active biosilicate technology. Biodentine sets in approximately 12 minute and is effective in pulp therapy, while being able to act as a coronal dentine replacement and can be used for the treatment of root and pulpal floor perforations, internal and external resorption, apical plug formation, root-end filling, pulp capping and pulpotomy but also for temporary sealing of cavities and cervical fillings ${ }^{(2)}$.

Despite biodentine's having desirable properties; there is room for improvement by incorporation of the caries inhibiting fluoride and strontium additives. Fluoride and strontium confers anticariogenic properties due to inhibition of plaque bacteria metabolism and impairing plaque bacteria adhesion and build up and formation of acid resistant fluorapatite crystals ${ }^{(1)}$. However, there is few data available regarding to these modification. So, hypothesis of this study was done that there will be an effect on evaluation of water sorption, solubility and $\mathrm{pH}$ of fluoride and strontium fluoride modified calcium silicate based cement.

\footnotetext{
* Assistant lecturer of Dental Biomaterials Department, Faculty of Dental Medicine, Assiut, Al-Azhar University.

** Professor and head of Dental Biomaterials Department, Faculty of Dental Medicine, Cairo, Boys, Al-Azhar University.

*** Assistant Professor of Dental Biomaterials Department, Faculty of Dental Medicine, Cairo, Boys, Al-Azhar University.
} 


\section{MATERIAL AND METHOD}

A total of 40 samples were prepared and equally divided into three main groups ( $\mathrm{n}=20$ samples) according to materials used. Group I: Calcium silicate based material (Septodont, Saint Maur des Fossés, France) is a control group (biodentine), Group II: Strontium fluoride modified calcium silicate based material (ADVENT, CHEBO PVT, LTO) and Group III: Fluoride modified calcium silicate based material (Prevest Den Pro Limited Unit 1,38 , Industrial Estate, Digiana, Jammu-180010, India). Each main group was subdivided into two subgroups according to test type ( $\mathrm{n}=20$ sample) $\mathrm{pH}$ and water sorption and solubility test. Water sorption and solubility test is considered as one test and used the same samples.

\section{Water sorption and Solubility test.}

In this study circular polytetrafluoroethylene split mold $(1.5 \mathrm{~mm}$ thickness and inner diameter of $7 \mathrm{~mm}$ ) were used for construction of the samples according to ISO $4049 ; 2009^{(3)}$.

Modification of biodentine was prepared by adding $10 \%$ by weight of fluoride and strontium fluoride to biodentine powder. Since biodentine powder weight is $0.7 \mathrm{gm}$. so the weight of fluoride and strontium fluoride added to the biodentine powder was calculated using the following equation $=(0.7 \times 10) / 100=0.07 \mathrm{gm}$.

Fluoride and strontium fluoride (0.07gm) modifiers were added to the biodentine powder and mixed it at 3000 RPM in the amalgamator for 10 seconds. This was to ensure dispersion of fluoride and strontium fluoride into the biodentine powder. Five drops of liquid added to the powder and triturating in amalgamator for 30 seconds in 3000 RPM leading to the formation of a paste of creamy consistency.

The mold was supported by a larger glass plate and covered with a polyester film. The material was prepared and filled the mold using a plastic spatula.
A nylon thread was placed inside the material and another glass plate also covered with polyester film in such a way that the plates touched the entire mold in a uniform manner. The material allow to set and placed in an incubator (3M, Advanced Technology) at $37^{\circ} \mathrm{C}, 95 \%$ relative humidity for a period corresponding to three times of the setting time.

\section{Measurement of water sorption and solubility of the materials:}

For water sorption test, the samples were suspended by nylon thread and placed inside a glass container containing $20 \mathrm{ml}$ of deionized distilled water and stored for 7 days in an incubator for $37{ }^{\circ} \mathrm{C}$, $95 \%$ relative humidity. The samples were weighed (initial weight) three times each using sensitive analytical balance with an accuracy of $0.0001 \mathrm{~g}$ (Sartorius, Bio-pharma Laboratory, Germany).

After 7 days, the samples were removed from distilled water and weighed again. Each weight measurement was repeated three times and the mean was recorded as the (wet weight). The water absorption at each time point was calculated as follows: Water absorption $=($ [wet weight after 7 days - initial weight]/ initial weight) x100.

Then, the samples were rinsed with deionized distilled water, blotted dry with absorbent paper, placed in desiccators for $24 \mathrm{~h}$ and then reweighted (dry weight). The experiment was repeated three times for each sample. The percentage of weight loss of each sample was considered as solubility of the material and calculated as follows: Solubility $=([$ dry weight after 7 days- initial weight $] /$ initial weight) $\mathrm{x} 100$.

\section{Determination of $\mathrm{pH}$ test:}

In this study circular polytetrafluoroethylene split mold $(1.5 \mathrm{~mm}$ thickness and inner diameter of $7 \mathrm{~mm}$ ) were used for construction of the samples as mention previously in water sorption test. 


\section{Measurement of pH for tested material:}

The mold was filled with freshly mixed material and immersed in $(10 \mathrm{ml})$ distilled water. The $\mathrm{pH}$ readings were performed using a waterproof calibrated digital pH-meter(AD11, Adwa, Romania) after 24 hour and one week and four weeks. At each period of analysis, the elution was collected for testing and replaced by fresh distilled water. Ten milliliters of distilled water was used as negative control ( $\mathrm{pH}=7$ approximately).

Data analysis was performed in several steps. Initially, descriptive statistics for each group results. Two way ANOVA was done for comparing cement and storage media effect on different variable studied. One way ANOVA followed by pair-wise Turkey's post-hoc tests were performed to detect significance between each cement groups and t-test for subgroups. Statistical analysis was performed using Assistant 7.6 statistics software for windows (Campina Grande, Paraiba state, Brazil). p values $\leq 0.05$ are considered to be statistically significant in all tests.

\section{RESULTS}

\section{Water sorption $(\%)$}

Water sorption (\%) results (Mean $\pm \mathrm{SD}$ ) measured as function material group are summarized in table (1). It was found that fluoride (F) modified biodentine group recorded statistically significant $(p<0.05)$ highest water sorption percentage mean values followed by strontium fluoride (SF) modified biodentine group while the lowest statistically significant $(p<0.05)$ water sorption percentage mean values was recorded for biodentine group as indicated by one way ANOVA test. Pair-wise Tukey's post-hoc tests showed no-significant $(p>0.05)$ difference between SF modified biodentine and biodentine group.
TABLE (1) Comparison between water sorption results (Mean $\pm \mathrm{SD}$ ) as function of material group

\begin{tabular}{|c|c|c|c|c|}
\hline \multicolumn{2}{|r|}{ Variable } & Mean $\pm \mathrm{SD}$ & Rank & ANOVA \\
\hline \multirow{3}{*}{ 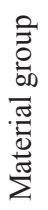 } & Biodentine & $6.85 \pm 0.92$ & B & $\mathrm{p}$ value \\
\hline & SF modified biodentine & $9.61 \pm 4.03$ & $\mathrm{~B}$ & \multirow{2}{*}{$0.0220 *$} \\
\hline & F modified biodentine & $15.12 \pm 4.22$ & $\mathrm{~A}$ & \\
\hline
\end{tabular}

Different letter indicating statistically significant difference $(p<0.05)$. ns; non-significant $(P>0.05) *$; significant $(P<0.05)$

\section{Solubility Percentage}

Solubility percentage results (Mean \pm SD) measured as function material group are summarized in table (2). It was found that $\mathrm{F}$ modified biodentine group recorded statistically significant $(\mathrm{p}<0.05)$ highest solubility percentage mean values followed by $\mathrm{SF}$ modified biodentine group while the lowest statistically significant $(p<0.05)$ solubility percentage mean values was recorded for biodentine group as indicated by one way ANOVA test. Pairwise Tukey's post-hoc tests showed no-significant $(p>0.05)$ difference between SF modified biodentine and biodentine group.

TABLE (2) Comparison between solubility results (Mean \pm SD) as function of material group

\begin{tabular}{|c|c|c|c|c|}
\hline \multicolumn{2}{|r|}{ Variable } & Mean \pm SD & Rank & ANOVA \\
\hline \multirow{3}{*}{ 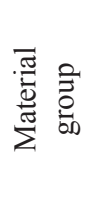 } & Biodentine & $2.94 \pm 0.09$ & B & $\mathrm{p}$ value \\
\hline & $\begin{array}{l}\text { SF modified } \\
\text { biodentine }\end{array}$ & $3.27 \pm 0.85$ & $\mathrm{~B}$ & \multirow[t]{2}{*}{$0.0006^{*}$} \\
\hline & F modified biodentine & $4.84 \pm 0.73$ & A & \\
\hline
\end{tabular}

Different letter indicating statistically significant difference $(p<0.05)$. ns; non-significant $(P>0.05) *$; significant $(P<0.05)$

\section{2. pH values}

$\mathrm{pH}$ values results (mean $\pm \mathrm{SD}$ ) as function of material groups and evaluation time are summarized in table (3). 
Biodentine group; it was found that $\mathrm{pH}$ recorded after $24 \mathrm{hrs}(10.57 \pm 1.18)$, after one week $(10.419 \pm 0.15)$ while after 4 weeks $(9.389 \pm 1.03)$. The difference in between evaluation time subgroups was non-significant $(\mathrm{p}>0.05)$

SF modified biodentine group; it was found that $\mathrm{pH}$ recorded after $24 \mathrm{hrs}(9.3 \pm 0.66)$, after one week $(8.53 \pm 0.77)$ while after 4 weeks $(7.87 \pm 1.43)$. The difference in between evaluation time subgroups was non-significant $(\mathrm{p}>0.05)$.

F modified biodentine group; it was found that $\mathrm{pH}$ recorded after $24 \mathrm{hrs}(11.04 \pm 0.64)$, after one week $(9.67 \pm 1.37)$ while after 4 weeks $(9.03 \pm 2.01)$. The difference in between evaluation time subgroups was non-significant $(\mathrm{p}>0.05)$.

Totally; material group influenced the $\mathrm{pH}$ value significantly $(p=0.007)$ where (biodentine $>F$ modified biodentine $>$ SF modified biodentine), also $\mathrm{pH}$ value declined by time significantly $(\mathrm{p}=0.01)$ as revealed by two-factorial ANOVA where ( $24 \mathrm{hrs}>$ one week $>4$ weeks).

TABLE (3) $\mathrm{pH}$ results (Mean $\pm \mathrm{SD}$ ) as function of material groups and evaluation time

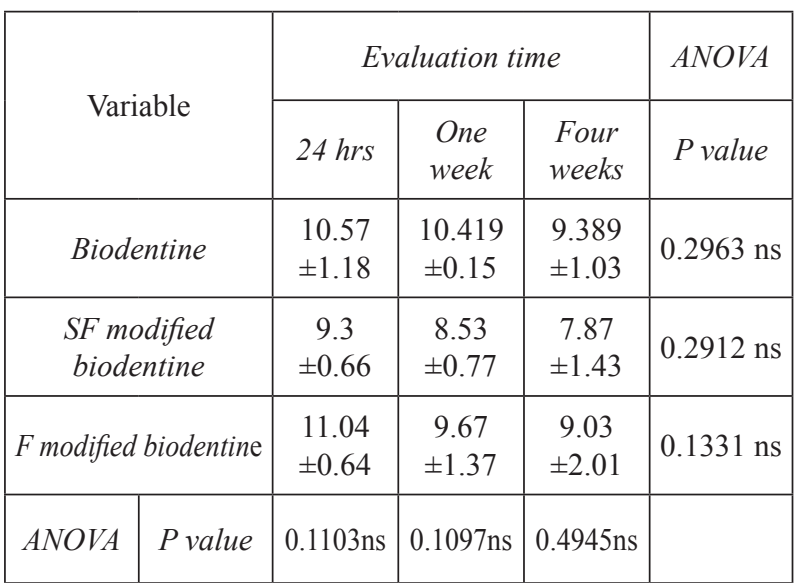

Different small letter in same column indicating statistically significant difference between materials $(p<0.05)$. *; significant $(P<0.05)$ ns; non-significant $(P>0.05)$

\section{DISCUSSION}

Biomaterials science aims to develop materials that are ideal mechanically, physically and biologically ${ }^{(1)}$. Several materials are being used as dentine replacement materials such as glass ionomer, resin modified glass ionomer, resin-composites and more recently water-based calcium silicate materials such as biodentine have been introduced. Although these materials are not directly exposed to the oral environment, they may be indirectly affected by oral fluids through microleakage, defective restoration margins or delaying final restoration placement. Despite biodentine have desirable properties; there is room for improvement by incorporation of the caries inhibiting fluoride and strontium species which anticariogenic properties due to inhibition of plaque bacteria metabolism and impairing plaque bacteria adhesion and build up and formation of acid resistant fluorapatite crystals ${ }^{(1)}$

Water sorption (the amount of water adsorbed on the surface and absorbed into the body of the material) (4). Absorption of water precedes events such as volumetric changes, swelling and tempering of the materials which may compromise their microstructure and as a consequence the seal produced by the restoration ${ }^{(5)}$.

The results of the present study showed lower water sorption of biodentine followed by strontium fluoride modified biodentine while fluoride modified biodentine has highest water sorption. The result of this study were in agreement with previous studies Camilleri et al. ${ }^{(6)}$, De Souza et al. (7). This could be attributed to more dense and less porous structure of biodentine which lead to the lowest fluid uptake and absorption of fluid Also could be attributed to the water reducing agent (superplasticizer) and the rapid hydration reaction in biodentine ${ }^{(8)}$.

Also O'donnell and Hill ${ }^{(9)}$ found that high water sorption of fluoride modified biodentine is attributed to high amount of fluoride ion release while 
strontium fluoride modified biodentine contain less amount of fluoride so water sorption is less. Amount of fluoride released is proportional to the amount of fluoride incorporated into the cements. Also presence of strontium promotes release of other ions which led to more space allow for water sorption. While biodentine does not contain any fluoride or strontium element so, water sorption is less.

On the other hand the result of this study disagree with Jalloul et al. ${ }^{(10)}$ who stated that the behavior of water sorption is mainly due to the increase of the non-evaporable water over time within the tricalcium silicates contained in biodentine.

Solubility (the amount of that substance that will dissolve in a given amount of solvent) ${ }^{(4)}$. It is an important factor in assessing the suitability of materials to be used as restorative materials in dentistry. Lack of solubility is a desired characteristic for root repair cements because endodontic and restorative materials should provide a long term seal and avoid leakage from the oral cavity and/or the periapical tissue ${ }^{(11)}$.

The results of the present study showed lower solubility of biodentine followed by strontium fluoride modified biodentine while fluoride modified biodentine has highest solubility. The result of this study was in agreement with previous studies Al-shekhli et al. (12) Mustafa et al. ${ }^{(13)}$. This may be attributed to calcium silicates material undergo two stage setting reaction. Stage one is marked by formation of a metastable phase of calcium silicate hydrate and calcium hydroxide followed by formation of semi-crystalline calcium silicate hydrate and calcium hydroxide. There is an induction period during which the metastable calcium silicate hydrate phase coats the tricalcium silicate particles and controls the rate at which precipitation of calcium silicate hydrate occurs ${ }^{(1)}$.

Also the hydration of calcium silicate cements proceeds by converting liquid (free) water (i.e., the mixing water) into structural and constrained water. Tricalcium silicate (the biodentine component) is very reactive and hydrates whereas dicalcium silicate hydrates slowly. Due to its fast hydration rate, tricalcium silicate solidifies rapidly providing a good early strength to the paste responsible for the low solubility obtained for biodentine ${ }^{(14)}$.

On the other hand the result of this study disagreement with Gandolfi et al ${ }^{(8)}$.who found that the biodentine is high soluble and that associated with high amounts of $\mathrm{Ca}$ and $\mathrm{Si}$ ion release which are important in its bioactivity.

In the $\mathrm{pH}$ test the presence of calcium compounds in a dental material does not imply their dissociation and release by the materials after setting because the setting reaction and the presence of other constituents can inhibit the release of calcium ions. Another factor which could inhibit/promote calcium ion release from the materials is a change of the $\mathrm{pH}$ of the environment during and after the setting of tricalcium silicate ${ }^{(15)}$.

The results of the present study showed that biodentine have a high $\mathrm{pH}$, followed by fluoride modified biodentine, followed by strontium fluoride modified biodentine). Also $\mathrm{pH}$ values declined by time where ( $24 \mathrm{hrs}>$ one week $>$ four weeks). The result of the present study was in agree with Quintana et al. ${ }^{(16)}$, Mullaguri et al. ${ }^{(17)}$. This could be attributed to the setting reaction of biodentine results in the formation of calcium silicate hydrate and calcium hydroxide. In the presence of moisture, calcium hydroxide dissociates to hydroxyl ions responsible for the increased alkalinity and antibacterial activity and calcium ions that promote material bioactivity and apatite layer formation. Also biodentine released significantly higher amounts calcium ions so, calcium ions release dropped with time ${ }^{(18)}$.

Also this may be attributed to presence of fluoride which lead to formation acid resistant fluorapatite which increase $\mathrm{pH}$. The improved acid resistance fluorapatite is attributed to the stronger electrostatic interaction between calcium and fluoride ions within the crystalline structure while in biodentine 
is attributed to the release of calcium hydroxide ions which raise $\mathrm{pH}^{(19)}$.

The hypothesis of this study was that the incorporation of strontium fluoride or fluoride will change the water sorption, solubility and $\mathrm{pH}$ biodentine, was partially accepted.

\section{CONCLUSIONS}

There was no single modification that achieved all levels of improvement on the tested properties, so modification of biodentine with strontium fluoride and fluoride have no considerable effect on the tested properties of biodentine.

\section{REFERENCES}

1. Simila Ho, Karpukhina N, Hill RG. Bioactivity and fluoride release of strontium and fluoride modified biodentine. Dental Materials. 2018;34(1):1-7.

2. Dammaschke T. Direct pulp capping. Dental Materials. 2011;27(8):88-94.

3. International Standardization for Organization (ISO). Dentistry-polymer-based Restorative Materials: ISO; 2009.

4. Grech L, Mallia B, Camilleri J. Investigation of the physical properties of tricalcium silicate cement-based root-end filling materials. Dental Materials. 2013;29(2):20-8.

5. Mayer T, Eickholz P. Microleakage of temporary restorations after thermocycling and mechanical loading. Journal of Endodontics. 1997;23(5):320-2.

6. Camilleri J, Sorrentino F, Damidot D. Investigation of the hydration and bioactivity of radiopacified tricalcium silicate cement, biodentine and MTA angelus. Dental materials. 2013;29(5):580-93.

7. De Souza ETG, Nunes Tameirão MD, Roter JM, De Assis JT, De Almeida Neves A, De-Deus GA. Tridimensional quantitative porosity characterization of three set calcium silicate-based repair cements for endodontic use. Microscopy research and technique. 2013;76(10):1093-98.

8. Gandolfi MG, Siboni F, Botero T, Bossù M, Riccitiello F, Prati C. Calcium silicate and calcium hydroxide materials for pulp capping: biointeractivity, porosity, solubility and bioactivity of current formulations. Journal of Applied Biomaterials and Functional Materials. 2015;13(1):43-60.
9. O'donnell M, Hill R. Influence of strontium and the importance of glass chemistry and structure when designing bioactive glasses for bone regeneration. Dental Materials. 2010;6(7):2382-85.

10. Jalloul D, Al Abdullah J, Alaffif H. The chemical and morphological study of calcium silicate-based material (biodentine) and glass ionomer cement. Open Dentistry Journal. 2018;12(1):23-30.

11. Torabinejad M, Hong C, McDonald F, Ford TP. Physical and chemical properties of a new root-end filling material. Journal of Endodontics. 1995;21(7):349-53.

12. AL-Shekhli Ar, Al-Jaafar Na, Al-Nuami Mm. Sorption and solubility of biodentine new restorative material. Pakistan Oral and Dental Journal. 2016;36(1):12-17.

13. Mustafa R, Alshali RZ, Silikas N. The effect of desiccation on water sorption, solubility and hygroscopic volumetric expansion of dentine replacement materials. Dental Materials. 2018;34(8):e205-e13.

14. Gandolfi M, Siboni F, Polimeni A, Bossù M, Riccitiello $\mathrm{F}$, Rengo $\mathrm{S}$, et al. In vitro screening of the apatite-forming ability, biointeractivity and physical properties of a tricalcium silicate material for endodontics and restorative dentistry. Dentistry Journal. 2013;1(4):41-60.

15. Rajasekharan S, Vercruysse C, Martens L, Verbeeck R. Effect of exposed surface area, volume and environmental $\mathrm{pH}$ on the calcium ion release of three commercially available tricalcium silicate based dental cements. Dental Materials. 2018;11(1):123-130.

16. Quintana RM, Jardine AP, Grechi TR, Grazziotin-Soares $\mathrm{R}$, Ardenghi DM, Scarparo RK, et al. Bone tissue reaction, setting time, solubility and $\mathrm{pH}$ of root repair materials. Clinical Oral Investigations. 2019;23(3):1359-66.

17. Mullaguri H, Suresh N, Surendran S, Velmurugan N, Chitra $\mathrm{S}$. Role of $\mathrm{pH}$ changes on transforming growth factor- $\beta 1$ release and on the fibrin architecture of platelet-rich fibrin when layered with biodentine, glass ionomer cement and intermediate restorative material. Journal of Endodontics. 2016;42(5):766-70.

18. Grech L, Mallia B, Camilleri J. Characterization of set intermediate restorative material, biodentine, bioaggregate and a prototype calcium silicate cement for use as rootend filling materials. International Endodontic Journal. 2013;46(7):632-41

19. Allen AJ, Thomas JJ, Jennings HM. Composition and density of nanoscale calcium-silicate-hydrate in cement. Dental materials. 2007;6 (4):311-28. 